\title{
Estimating the dispersal potential of polychaete species in the Southern California Bight: implications for designing marine reserves
}

\author{
Henry S. Carson*, Brian T. Hentschel \\ Department of Biology, San Diego State University, 5500 Campanile Drive, San Diego, California 92182-4614, USA
}

\begin{abstract}
Using known and inferred life-history information, we estimated the dispersal potential of 501 polychaete species sampled during a 1998 monitoring study in the Southern California Bight. We tested the hypothesis that species having life-history traits that suggest long-distance dispersal will be encountered more frequently throughout the region than will species having life histories that suggest limited dispersal. When all 501 species and all 200 sampling sites were analyzed, occurrence frequency (percentage of sites at which a species was collected) was not significantly related to dispersal potential. When data from 53 shelf sites in the Channel Islands were analyzed separately from collections at 147 mainland-shelf sites, there was a significant positive relationship between dispersal potential and occurrence frequency at the island sites but not at the mainland sites. Of the 501 species, 119 were collected only at island sites, 98 were found only at mainland sites, and 284 were found at both island and mainland sites. The majority of the 'island only' species had life-history traits indicating low dispersal potential. In contrast, only $13 \%$ of the 'mainland only' species were categorized as having low dispersal potential. The 'cosmopolitan' species had a broad range of dispersal potential. Models indicate that efforts to conserve biodiversity by establishing Marine Protected Areas (MPAs) must consider species' dispersal. In the shelf communities of the Southern California Bight, networks of small reserves that are located in existing areas of high diversity should succeed in the Channel Islands, where the majority of polychaete species tend to have limited dispersal potential. On the mainland shelf, however, designing effective MPAs will be more challenging due to the prevalence of species that have a greater potential for long-distance dispersal to or from unprotected sites.
\end{abstract}

KEY WORDS: Dispersal $\cdot$ Larval ecology $\cdot$ Life history $\cdot$ Marine Protected Area $\cdot$ Marine reserve Polychaete Resale or republication not permitted without written consent of the publisher

\section{INTRODUCTION}

The life histories of most marine organisms include a planktonic larva that has the potential to disperse away from the parental habitat. The ability of these larvae to disperse and successfully recruit to suitable habitats affects the demography (Strathmann 1985) and interrelatedness (Hellberg 1996, Bohonak 1999) of local populations. When patches of suitable habitat are discontinuous in time and space, the distance over which an organism is able to disperse will greatly affect its ability to colonize new habitats or recover from disturbance (Gunther 1992, Shull 1997, Whitlatch et al. 1998).

Directly determining the dispersal distances for marine organisms is difficult due to the vastness of the potential dispersal area and the large numbers and high mortality of microscopic larvae (Rumrill 1990, Thurrold et al. 2002). Until dispersal is tested directly in the field using recently developed tagging technology (reviewed by Thurrold et al. 2002), the dispersal of organisms must be estimated using other methods, 
such as an examination of species' life histories. For example, the duration of a planktonic larval period is known to correlate with dispersal distance (Shanks et al. 2003).

Previous studies have applied life-history information to estimate the dispersal potential of organisms in relation to specific habitats. Parker \& Tunnicliffe (1994) assessed the dispersal potential of the species encountered on a seamount off the coast of Oregon, attempting to find a common dispersal strategy that resulted in those species' accumulation in that isolated habitat. Grantham et al. (2003) examined 91 species lists of macroinvertebrates in 7 rocky and sandy habitats along the US Pacific Coast and demonstrated that dispersal profiles differed between the species inhabiting rocky and sandy substrates.

Polychaete worms are among the most abundant organisms in many soft-sediment communities. Polychaetes also show an amazing diversity of life-history strategies, from brooded direct development to swimming larvae that spend weeks in the plankton (Wilson 1991a). Polychaetes often are among the first colonists of disturbed habitats (e.g. Shull 1997) and affect later succession in soft-sediment communities (e.g. Gallagher et al. 1983, Thrush et al. 1996). Polychaetes also are common items in the diets of species that have greater socioeconomic value, such as commercial fishes (e.g. Stehlik $\&$ Meise 2000). Although polychaetes and other infauna do not receive much attention from lay audiences, ecologists have long recognized that these diverse worms are central to the functioning of marine ecosystems (e.g. Wilson 1991b, Waldbusser et al. 2004).

In recent years, strict 'marine reserves' (Lubchenco et al. 2003) have become a popular tool for managing some fisheries and are often designated the broader goals of conserving biodiversity and ecosystem functioning (Palumbi 2003, Roberts et al. 2003). To achieve these objectives, networks of marine reserves and less restrictive Marine Protected Areas (hereafter MPAs) must be designed to include heterogeneous habitats and facilitate sustainable populations of many diverse species (Sala et al. 2002, Airame et al. 2003, Roberts et al. 2003). Not surprisingly, the soft sediments of continental shelves have received much less attention than other habitats such as seagrass meadows, kelp forests, and rocky coasts (e.g. Airame et al. 2003). Similarly, protecting the diversity of polychaetes and other infauna has been a lower priority relative to the conservation of marine mammals, seabirds, and commercially exploited species (e.g. Airame et al. 2003). Because the varying dispersal distances of diverse species pose one of the greatest challenges to designing effective networks of MPAs (Gaines et al. 2003, Grantham et al. 2003, Kinlan \& Gaines 2003, Palumbi 2003, Shanks et al. 2003), any effort to conserve biodiversity and eco- system functioning by establishing MPAs that include soft-sediment communities will be more likely to succeed if the designs of MPA networks incorporate knowledge about the dispersal potential of common infaunal taxa, such as polychaetes.

A regional network of MPAs has been proposed to aid in the conservation of marine biodiversity in the Southern California Bight (California Fish \& Game 2002, Abeles et al. 2003, Airame et al. 2003). In particular, the Channel Islands National Marine Sanctuary (CINMS), which includes marine reserves and less restrictive MPAs, protects the waters around San Miguel, Santa Rosa, Santa Cruz, Anacapa and Santa Barbara Islands. Together with Santa Catalina Island, which lies outside the Sanctuary, the 6 island shelves have a total of $2139 \mathrm{~km}^{-2}$ of benthic habitat (Ranasinghe et al. 2003). These islands straddle an important ecological boundary where currents flowing southeast from the cold-water, northern marine communities meet the warmer currents flowing northwest from southern California (Hewatt 1946). This may contribute to greater species diversity in the island shelves, as eddies from the 2 water masses mix pelagic larvae from both regions. Hewatt (1946) found that about $20 \%$ of the species he collected on Santa Cruz Island were at the approximate northern or southern extent of their range. Although many factors must be considered when selecting locations for additional MPAs in the Southern California Bight and designating which sites within existing MPAs should become more restrictive marine reserves (e.g. Airame et al. 2003, Roberts et al. 2003), a network of MPAs is unlikely to protect the region's biodiversity unless the size, spacing, and location of various MPAs are based, in part, on knowledge about the dispersal of species in the region.

In this paper, we apply existing knowledge of polychaete life histories to assess the dispersal potential of 501 polychaete species found in the mainland or island-shelf communities of the Southern California Bight (Ranasinghe et al. 2003). We found that $43 \%$ of the polychaete species were collected at island or mainland sites, but not at both. In particular, we examined the hypothesis that species having a greater dispersal potential should occur more frequently across the region than do species having a lower dispersal potential. Our analysis reveals that the majority of polychaete species collected from island-shelf sites tend to have limited potential for dispersal, while the majority of species collected from the mainland shelf have a greater potential for dispersal. These analyses suggest that both island and mainland sites must be included in a regional MPA network and that the size of and spacing between MPAs might need to differ considerably at island and mainland locations in the Southern California Bight. 


\section{MATERIALS AND METHODS}

The Southern California Bight Regional Monitoring Project sampled 147 soft-sediment benthic sites from the continental shelf off the southern California coast between Point Conception and the US-Mexico border in 1998 (Fig. 1; Ranasinghe et al. 2003). An additional 53 samples were taken from the shelves off the 5 Channel Islands and Santa Catalina Island (Fig. 1). This project also sampled benthic communities in Mexican waters and embayments of the US mainland, but these samples were excluded from our analysis. Ranasinghe et al. (2003) describe the experimental design, sampling, and laboratory procedures in detail. Sites were chosen using a random tessellation stratified design, and organisms collected using a $0.1 \mathrm{~m}^{-2}$ Van Veen grab sieved through a $1 \mathrm{~mm}$ mesh. It should be noted that this mesh size probably excluded several species of polychaetes from the analysis. Sample depths ranged from 10 to $120 \mathrm{~m}$ depth. Collected organisms were preserved and stored for laboratory identification. Workers keyed the samples to the lowest taxonomic level possible, using the taxonomic scheme of the Southern California Association of Marine Invertebrate Taxonomists.

We divided the resulting list of 501 polychaete species (Ranasinghe et al. 2003) into 3 dispersal potential cate- gories: 'high', 'medium', and 'low' (Table 1) based on these species' known life-history parameters or inferences based on the life histories of closely related species (Appendix 1; available at: www.int-res.com/articles/ suppl/m316p105_app.pdf). The dispersal potential of some species was listed as 'undetermined' either because we could find little or no life-history information about the species and closely related taxa, or because closely related species exhibited a wide range of life histories that prevented reasonable extrapolation.

The high-dispersal category includes species that can potentially disperse tens of kilometers and exchange larvae with distant populations. These species can be considered to have 'open' marine populations (Roughgarden et al. 1985, Caley et al. 1996). The medium-dispersal category implies dispersal on the scale of kilometers. These demographic populations will normally be contained on 1 island or island group. Large barriers to dispersal, such as extended stretches of unsuitable habitat, may divide the mainland shelf into demographically distinct units in this group as well. The low-dispersal category, most likely less than $1 \mathrm{~km}$, denotes species that have relatively 'closed' populations (Roughgarden et al. 1985, Caley et al. 1996). Because the larvae of low-dispersing populations are retained close to their parents, the shelf of a single island or stretch of mainland coast may contain several

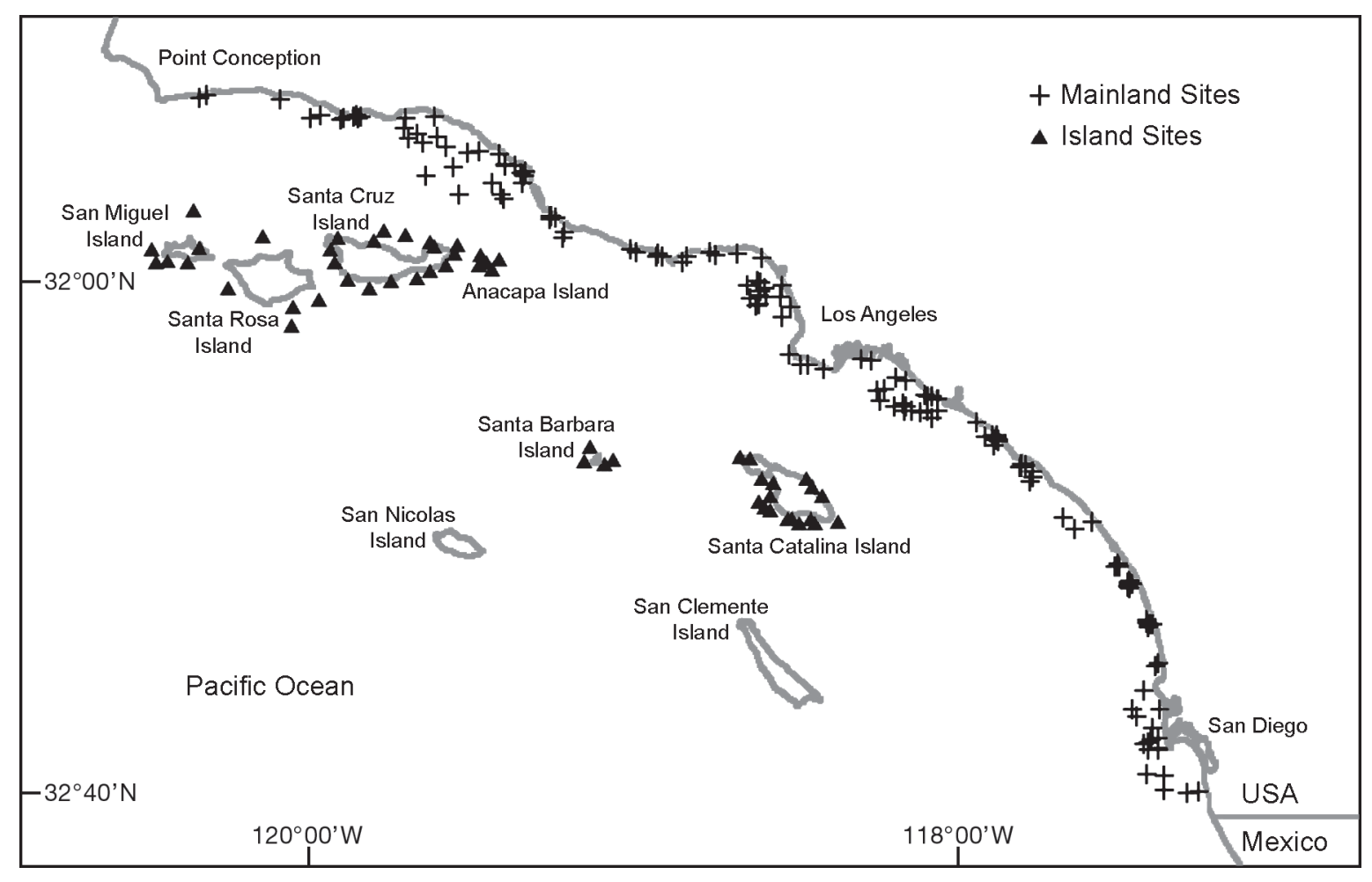

Fig. 1. Southern California Bight Regional Monitoring Project sites used in the analysis of polychaete life histories and dispersal (modified from Ranasinghe et al. 2003) 
Table 1. Polychaete species in the Southern California Bight. Mean occurrence frequencies $( \pm \mathrm{SD})$ of all species that were assigned to each dispersal-potential category based on known or inferred life-history traits. Occurrence frequency is the percentage of all 200 sampling sites at which a given species was collected (see Appendix 1; available at: www.int-res.com/ articles/suppl/m316p105_app.pdf)

\begin{tabular}{|lcc|}
\hline $\begin{array}{l}\text { Dispersal } \\
\text { potential }\end{array}$ & $\begin{array}{c}\text { No. } \\
\text { of species }\end{array}$ & $\begin{array}{c}\text { Occurrence frequency } \\
(\%)\end{array}$ \\
\hline High & 128 & $11.2( \pm 16.5)$ \\
Medium & 93 & $9.4( \pm 13.6)$ \\
Low & 123 & $7.1( \pm 9.8)$ \\
Undetermined & 157 & $5.6( \pm 8.0)$ \\
Total & 501 & $8.1( \pm 12.3)$ \\
\hline
\end{tabular}

demographically and genetically independent populations of these species.

Several life-history characteristics were used in our analysis: method of fertilization, extent of brooding (either in or on the body or in egg masses), method of dispersal, feeding behavior of the larvae, average time before settlement, mobility of adults, and presence or absence of epitokous reproduction. Not all characteristics were given equal weight. Some life-history characteristics provided very clear indications of dispersal potential. For example, species that have crawling larvae or direct development were always assigned a low dispersal potential (Hellberg 1996). For most taxa, however, a suite of known life-history information was considered.

The most important estimator of dispersal for pelagic developers was time before settlement. If this is known, oceanographic information can be incorporated to estimate dispersal in terms of actual distances (e.g. Gaines et al. 2003). Unfortunately, the duration of the pelagic larval period was known for very few species (22 of 501).

For most taxa in our analysis, time before settlement was inferred from the feeding mode of larvae. Planktotrophic larvae, which feed during their pelagic development, tend to have greater dispersal distances relative to lecithotrophic larvae, which metabolize stored energy reserves (Strathmann 1985, Todd 1998). In Grantham et al. (2003), for example, average time in the plankton was known for 5 polychaete planktotrophs and 17 polychaete lecithotrophs. The planktotrophs averaged $57 \mathrm{~d}$ in the plankton (range: 13 to $150 \mathrm{~d}$ ), which allows for dispersal of tens or hundreds of kilometers. Lecithotrophs averaged just $7 \mathrm{~d}$ before settlement (range: 1 to $25 \mathrm{~d}$ ), suggesting more modest dispersal.

Because the dispersal distances of mobile adults are usually several orders of magnitude less than the distances planktonic larvae can travel (reviewed by Gunther 1992), the mobility of adult polychaetes was given less weight when estimating dispersal potential. Epitoky, the budding of a sexual stage to search for a suitable mate, can be another source of dispersal, but also was given less weight because epitokes and adults usually swim for brief periods at night and travel on the order of $1 \mathrm{~km}$ or less (e.g. Hobson \& Chess 1976, Dean 1978). A final method of dispersal, rafting, is used by some otherwise immobile species to disperse. Eggs, larvae, or adults attached to drifting plants or other material are transported by currents. Rafting potential has been identified for some species in the family Nereididae (Grantham et al. 2003).

In general, species with pelagic, planktotrophic development were assigned to the high-dispersal category. Species with pelagic but lecithotrophic larvae or evidence of a pelagic period of $<10 \mathrm{~d}$ were assigned to the medium-dispersal category. All other species for which key life-history characteristics were known were considered to have a low dispersal potential.

All relevant life-history characteristics, including method of fertilization, location of larval development, and average time spent in the plankton were known for a very small percentage of species listed in the survey. Our analysis was further complicated because not all polychaetes were keyed to the level of species (Ranasinghe et al. 2003). Often, however, 1 or more of these characteristics was known for a species in the same genera or family as the species in question. Only when at least $80 \%$ of known members of a taxon shared the same life-history characteristics were those characteristics assigned to an unknown species in that taxon. Otherwise, a diversity of life histories within the group relegated the unknown species to the undetermined category.

To test the hypothesis that polychaete species having a greater dispersal potential should occur more frequently across the region than do species having a lower dispersal potential, we calculated the occurrence frequency for each species by dividing the number of sites in which a species was collected by the total number of sites sampled (200). We also divided the sites into mainland (147) and island (53) shelves and recalculated the occurrence frequencies separately for each subset of sampling sites. Because the distribution of occurrence frequencies was heavily skewed toward low values, we tested for differences among dispersal categories using a nonparametric Kruskal-Wallis test (Zar 1999).

We also tested the hypothesis that species restricted to either the island or the mainland sites would have different dispersal potentials. We determined which species were collected at either island or mainland sites, but not both. The numbers of high, medium, and low dispersing species for the 'island-only' and 'mainland-only' groups were compiled in a $2 \times 3$ contin- 
gency table and compared with a chi-square test (Zar 1999). We also used chi-square tests to compare the dispersal potentials of the species that were collected at both island and mainland sites to those of either the 'island only' or the 'mainland only' species.

\section{RESULTS}

The data set included 49 polychaete families, 226 genera, and 501 different polychaete species (Appendix 1; Ranasinghe et al. 2003). Most of the species (302 of 501) were identified to described species. Of the remaining 199 species, 110 were denoted as different species within a genus (Appendix 1: 'Species A, B, C', etc.) and 89 were keyed to distinct genera that were each represented by what appeared to be a single species (Ranasinghe et al. 2003). A total of 403 of the 501 different species in the data set were collected from sites on the island shelves, and 382 species were collected from mainland-shelf sites. Samples from the 53 island sites included 119 species that were not collected at any of the 147 mainland sites. Conversely, 98 species were collected at mainland sites but not at island sites. A slight majority of the species (284 of 501) were found on both island and mainland shelves. We refer to these 3 groups as 119 'island-only' species, 98 'mainland-only' species, and 284 'cosmopolitan' species. Species-accumulation curves further show that the island sites contained a greater number of polychaete species, and the lack of an asymptote in the island data suggests that increasing the sampling effort on the island shelf probably would result in collecting additional 'island-only' species (Fig. 2).
Based on literature accounts of polychaete life histories, we were able to know or infer the dispersal potential of 344 of the 501 species (Appendix 1). Of the 344 species assigned to the 'high', 'medium' or 'low' dispersal-potential categories, 92 had known life-history traits or belonged to families in which all members that have been studied share the same life-history traits. Inferences about the dispersal potential of the remaining 252 species are less certain due to some variability of the known life-history traits among species within a family or genus (Appendix 1). Of the 49 families, 13 had no published information on reproduction and development: Acoetidae (2 spp.), Acrocirridae (3 spp.), Cossuridae (3 spp.), Fauveliopsidae (2 spp.), Lacydoniidae (1 sp.), Longosomatidae (1 sp.), Oenionidae (8 spp.), Paraonidae (27 spp.), Pholoidae (2 spp.), Pilargidae (9 spp.), Questidae (1 sp.), Saccocirridae (1 sp.) and Sternapsidae (1 spp.). Appendix 1 summarizes the known life-history characteristics, inferred dispersal potentials, frequencies of occurrence, and literature references for each of the 501 species.

Of the 344 species that could be assigned to dispersalpotential categories based on published life-history data, 128 were designated as 'high' dispersers, 93 as 'medium' dispersers, and 123 as 'low' dispersers (Table 1). On average, the 128 species in the high dispersal-potential category occurred at $11.2 \%$ of the 200 sampling sites (Table 1). The 93 species in the medium category and the 123 species in the low category were found at fewer sites on average (9.4 and $7.1 \%$, respectively: Table 1). As predicted, the average occurrence frequencies tended to decline as the inferred dispersal potential decreased, but the high, medium, and low categories did not have significantly different occurrence frequencies $(p=0.272$, Kruskal-Wallis test). The 157 species that could not be assigned to dispersal-potential categories occurred at $5.6 \%$ of the 200 sites; the lack of published information on these species' life histories can be explained largely because these species are relatively uncommon.

Because there are many oceanographic and ecological differences between the 53 island and 147 mainland locations, we decided a priori to analyze each of the 2 sampling areas separately. Of the 403 species collected at island sites, 96 were designated as high dispersers, 64 as medium dispersers, and 114 as low dispersers (Table 2). Species in the high, medium, and low dispersalpotential categories had significantly different occurrence frequencies on the island shelf ( $p=0.031$, Kruskal-Wallis test). On average, species in the high dispersal-potential category occurred at

Fig. 2. Species-accumulation curves for mainland and island sampling sites. Curves created with EstimateS version 7.5 (Colwell 2005) 
$14.6 \%$ of the 53 island sites. Species in the medium and low dispersal categories occurred at 12.1 and $9.0 \%$ of the 53 island sites, respectively (Table 2 ). Of the 382 species collected at mainland sites, 114 were designated as high dispersers, 78 as medium dispersers, and 82 as low dispersers (Table 2). Although species in the high dispersalpotential category tended to occur more frequently than medium and low dispersers at the 147 mainland sites (Table 2), the slight differences among the 3 dispersalpotential categories were not significant at the mainland sites ( $p=0.987$, Kruskal-Wallis test).

The occurrence frequencies also differed between the 'island-only' species, 'mainland-only' species, and 'cosmopolitan' species (Table 3). On average, the 284 'cosmopolitan' species occurred at $13.3 \%$ of the 200 sites. This occurrence frequency is significantly greater than that of either the 119 'island-only' species, which occurred at $3.7 \%$ of the 53 island sites $(p<0.001$, Mann-Whitney $U$-test) or the 98 'mainland-only' species, which occurred at $2.6 \%$ of the 147 mainland sites ( $\mathrm{p}<0.001$, Mann-Whitney $U$-test). The occurrence frequencies of the 'island-only' and 'mainland-only' species also differed significantly ( $\mathrm{p}<0.001$, MannWhitney $U$-test).

Most importantly, the 'island-only', 'mainland-only', and 'cosmopolitan' species showed different patterns of dispersal potential. Of the 119 'island-only' species, 70 were assigned to dispersal-potential categories; the majority of these species had life-history traits that suggested a low dispersal potential (Table 3). In contrast, the 98 'mainland-only' species tended to have high or medium dispersal potential; only 9 of the 70 categorized 'mainland-only' species were assigned to the low dispersal-potential category (Table 3). The frequency distribution of species in the high, medium, and low dispersal-potential categories differed significantly between the 'island-only' and 'mainland-only' groups $(\mathrm{p}<0.001$, chi-square $=31.978)$. Of the 284 'cosmopolitan' species, 204 could be assigned to dispersal-

Table 2. Polychaete species in the Southern California Bight. Mean occurrence frequencies $( \pm \mathrm{SD})$ of all species that were assigned to each dispersal-potential category when occurrence frequency is calculated separately for the 53 island sites or the 147 mainland sites. Occurrence frequency is the percentage of island or mainland sampling sites at which a given species was collected (see Appendix 1; available at: www.int-res.com/articles/suppl/m316p105_app.pdf)

\begin{tabular}{|lcccc|}
\hline $\begin{array}{l}\text { Dispersal } \\
\text { potential }\end{array}$ & $\begin{array}{c}\text { Island shelf (53 sites) } \\
\text { No. of } \\
\text { species }\end{array}$ & $\begin{array}{c}\text { Mccurrence } \\
\text { frequency (\%) } \\
\text { at island shelf }\end{array}$ & $\begin{array}{c}\text { Mo. of } \\
\text { species }\end{array}$ & $\begin{array}{c}\text { Occurrence } \\
\text { frequency (\%) at } \\
\text { mainland shelf }\end{array}$ \\
\hline High & 96 & $14.6( \pm 16.6)$ & 114 & $12.7( \pm 18.2)$ \\
Medium & 64 & $12.1( \pm 13.7)$ & 78 & $11.7( \pm 15.9)$ \\
Low & 114 & $9.0( \pm 9.0)$ & 82 & $10.0( \pm 12.8)$ \\
Undetermined & 129 & $8.7( \pm 10.2)$ & 108 & $7.4( \pm 9.6)$ \\
Total & 403 & $10.7( \pm 12.5)$ & 382 & $10.4( \pm 14.5)$ \\
\hline
\end{tabular}

potential categories. As one would expect, the majority of these 'cosmopolitan' species were in the high and medium dispersal-potential categories, but surprisingly 73 of the 204 species were designated as 'low' dispersers (Table 3). The frequency distribution of species in the high, medium, and low dispersal-potential categories differed significantly between the 'cosmopolitan' and 'island-only' groups ( $\mathrm{p}=0.003$, chisquare $=12.722$ ) and between the 'cosmopolitan' and 'mainland-only' groups ( $\mathrm{p}<0.001$, chi-square $=15.085)$.

\section{DISCUSSION}

The dispersal of larvae poses one of the greatest challenges to designing MPAs as effective tools for conserving biodiversity (Gaines et al. 2003, Grantham et al. 2003, Kinlan \& Gaines 2003, Palumbi 2003, Shanks et al. 2003). Our analysis of soft-sediment polychaetes in the Southern California Bight reveals that a regional network of MPAs must include both mainland and island sites. More importantly, our analysis suggests that the sizes and spacing of MPAs should be designed and managed somewhat differently in island and mainland shelves in the region.

Samples from sites in the Channel Islands included 119 polychaete species that were not collected from any of the mainland sites. The majority of these 'island-only' species had life-history traits that suggest a limited potential for larval dispersal. Sustainable populations of many low-dispersing species are likely to be protected in the Channel Islands if relatively small MPAs are located in sites that presently have high biodiversity. Because much of the island shelf already lies within the CINMS, in which oil and mineral exploration are prohibited, the major question associated with MPAs in the Channel Islands is whether certain sites should be managed as more restrictive marine reserves in which additional activities such as bottom trawling are prohibited (CINMS 2005). Gaining broad support for small reserves is often easier and requires fewer political compromises than establishing larger reserves (Roberts et al. 2003). Presently, $20 \%$ of the CINMS has been designated as marine reserves (CINMS 2005). Our analysis suggests that a network of small reserves in the Channel Islands is likely to protect many of the infaunal species that have limited dispersal.

In contrast, our analysis suggests that MPAs are much less likely to be effective at conserving infaunal diversity along the mainland shelf. The 98 polychaete species that were collected from main- 
Table 3. Polychaete species in the Southern California Bight. Mean occurrence frequencies $( \pm$ SD) of species that were collected from island sites but not any of the mainland sites ('island-only' species), species collected at mainland sites but not any of the island sites ('mainland-only' species), and species collected from both island and mainland sites ('cosmopolitan' species). Occurrence frequency is the percentage of the total sampling sites at which a given species was collected (see Appendix 1 ; available at: www.int-res.com/articles/suppl/m316p105_app.pdf). The occurrence frequencies of 'island-only' and 'mainland-only' species were calculated conservatively at a total of 53 island sites or 147 mainland sites, respectively. Occurrence frequencies of the 'cosmopolitan' species were calculated at all 200 sites in the region

\begin{tabular}{|c|c|c|c|c|c|c|}
\hline \multirow[t]{2}{*}{$\begin{array}{l}\text { Dispersal } \\
\text { potential }\end{array}$} & \multicolumn{2}{|c|}{$\begin{array}{l}\text { 'Island-only' species } \\
\text { (53 island sites) }\end{array}$} & \multicolumn{2}{|c|}{$\begin{array}{l}\text { ‘Mainland-only' species } \\
\text { (147 mainland sites) }\end{array}$} & \multicolumn{2}{|c|}{$\begin{array}{l}\text { Cosmopolitan species } \\
\text { (all } 200 \text { sites) }\end{array}$} \\
\hline & $\begin{array}{l}\text { No. of } \\
\text { species }\end{array}$ & $\begin{array}{l}\text { Occurrence } \\
\text { freq. (\%) at } \\
\text { island shelf }\end{array}$ & $\begin{array}{l}\text { No. of } \\
\text { species }\end{array}$ & $\begin{array}{l}\text { Occurrence } \\
\text { freq. (\%) at } \\
\text { mainland shelf }\end{array}$ & $\begin{array}{l}\text { No. of } \\
\text { species }\end{array}$ & $\begin{array}{l}\text { Occurrence } \\
\text { freq. (\%) at } \\
\text { all sites }\end{array}$ \\
\hline High & 14 & $4.7( \pm 3.1)$ & 32 & $2.1( \pm 3.1)$ & 82 & $16.7( \pm 18.4)$ \\
\hline Medium & 15 & $2.9( \pm 2.4)$ & 29 & $3.0( \pm 4.1)$ & 49 & $16.3( \pm 15.7)$ \\
\hline Low & 41 & $3.7( \pm 2.5)$ & 9 & $3.4( \pm 2.9)$ & 73 & $11.1( \pm 11.1)$ \\
\hline Undetermined & 49 & $3.6( \pm 2.7)$ & 28 & $2.5( \pm 2.8)$ & 80 & $9.8( \pm 9.5)$ \\
\hline Total & 119 & $3.7( \pm 2.6)$ & 98 & $2.6( \pm 3.3)$ & 284 & $13.3( \pm 14.3)$ \\
\hline
\end{tabular}

land sites but were not found at any of the island sites tended to have life-history traits that suggest a greater potential for larval dispersal than the majority of 'islandonly' species. To sustain open populations, MPAs must either be relatively large in size or managed as networks of connected smaller MPAs that protect both spawning sites and recruitment sites (e.g. Stockhausen et al. 2000, Gaines et al. 2003, Palumbi 2003). Balancing the many criteria for locating and managing MPAs can be especially challenging when sites must either be large or ecologically connected to other MPAs in the region (Airame et al. 2003, Roberts et al. 2003). Along the mainland shelf, isolated small reserves and 'areas of special biological significance' that limit local pollution are unlikely to sustain populations of the many polychaete species that disperse beyond the boundaries of any one reserve because the vast majority of widely dispersing larvae will be unlikely to settle in other small reserves where recruits are likely to survive and reproduce (Allison et al. 1998, Botsford et al. 2001).

Although our analysis of polychaete life histories suggests that MPAs are more likely to be effective in the island shelves than in the mainland shelf, conservationists must recognize that a regional network of MPAs will never protect all species. Both island and mainland sites included many rare species that occurred at just a few sites (Appendix 1). The speciesaccumulation curve of the island-shelf data suggests that increased sampling effort around the Channel Islands probably would result in collecting additional rare species (Fig. 2). Although uncommon infaunal species usually do not attract public attention, these rare species are arguably the ones most in need of protection if the goal is to conserve biodiversity, per se. Polychaetes and other infauna inhabiting shelf communities face a variety of threats caused by trawling, oil and gas exploration, chemical pollution, and inva- sive species. MPAs have the potential to protect populations of rare species if MPAs are located where the rare species occur and the species have limited dispersal. In contrast, MPAs generally will be very ineffective at protecting rare infaunal species that disperse great distances.

Because ocean currents have large effects on pelagic dispersal, efforts to locate and manage MPAs must interpret life-history trends in the context of oceanographic features on a variety of scales. Large-scale oceanographic trends suggest a high degree of larval exchange across the Southern California Bight. At different times of the year water moves north, south, seaward and landward past the Channel Islands, depending on the flow of the southward California Current, associated upwelling and relaxation events, and the formation of the northward-flowing Southern California Countercurrent (Lynn \& Simpson 1987). It is not surprising, therefore, that over half of all polychaete species in our analysis were found on both island and mainland shelves.

The presence of many rare species in each of the dispersal-potential categories suggests that a variety of small-scale oceanographic features and species-specific interactions with oceanographic conditions also must be understood and considered in the design and management of a regional MPA network. Recirculating currents and coastal boundary layers may help retain larvae near their point of origin even during long planktonic durations (Largier 2003). When Parker \& Tunnicliffe (1994) found that many species inhabiting an isolated seamount had a high potential for dispersal, they hypothesized that oceanographic forces must play a role in the persistence of these species at the seamount. Several other studies have provided evidence of self-recruitment despite a population's potential for longer-range dispersal (e.g. Todd 1998, 
Swearer et al. 2002). In particular, Kingsford et al. (2002) showed that swimming polychaete larvae are able respond to visual and chemical cues, as well as changes in water movement, salinity, and pressure, all of which may contribute to a discrepancy between theoretical (passive) dispersal and actual dispersal.

In general, diverse life histories in a community and oceanographic variability on a variety of spatial and temporal scales probably will doom any regional network of MPAs that promises to conserve biodiversity. Furthermore, MPAs designed to protect a subset of the community, will not necessarily protect the majority of species in a region. For example, Sala et al. (2002) developed a comprehensive model for locating marine reserves in the Gulf of California. Their design criteria focused on commercial reef fishes and explicitly assumed that a reserve network designed to protect these prominent species would also protect invertebrates and algae that have different life histories and dispersal distances than the targeted fishes. Our analysis and similar analyses (e.g. Grantham et al. 2003) suggest that such assumptions might be too simplistic, especially if the objective of an MPA network is to preserve biodiversity. Including a wide mix of habitat types within a reserve network (e.g. Sala et al. 2002) can be an effective bet-hedging strategy, but only if the habitat requirements of rare species are well understood. Shelf-sediment habitats have only a few variables that can be measured routinely (e.g. grain size, organic content, depth, flow regime), and the ecological niches of most infauna are less clear to ecologists than those of many hard-substrate species (Wilson 1991b, Snelgrove \& Butman 1994). While considerable progress has been made toward understanding the spatial and temporal nature of source-sink dynamics in populations of commercially important marine species (e.g. Stockhausen et al. 2000, Taylor 2004), similar efforts aimed at less conspicuous infaunal species that play key roles in the functioning of ecosystems have yet to occur.

Estimating dispersal potential from an incomplete set of life-history characteristics is a difficult task. The diverse life histories of polychaetes magnify the problem. Most all families have a variety of radically different life histories; the species within many genera have similarly diverse modes of reproduction and dispersal potentials. Furthermore, some polychaete species have demonstrated varying reproductive and developmental behavior across geographic ranges and within a single site (e.g. Levin \& Huggett 1990). Assigning characteristics to a poorly studied species using knowledge from other species in the family or genus, therefore, amounts to an educated guess at best.

Much work is left to do to understand the dispersal of polychaetes and other infaunal taxa. First, the reproductive and developmental biology of more species must be described. This is especially critical for infaunal species that play key roles in communities such as creating biogenic structures like tubes and mounds, providing major food items for other species, and affecting sediment chemistry. Secondly, new advances in larval tagging technology (review in Thurrold et al. 2002) must be incorporated into field trials to test hypothesized dispersal potentials by measuring larval dispersal directly. Lastly, assays of population genetics must be performed on many more infaunal species to place the exchange of larvae between groups in a greater temporal context. Only when we understand the minimum size of sustainable populations and the ability of populations to supply larvae to other areas can conservation efforts, such as the design of MPAs, be effective at maintaining biodiversity.

Acknowledgements. We thank the researchers, taxonomists and funding agencies of the Southern California Bight Regional Monitoring Project and the Southern California Coastal Water Research Project for providing the data on which this analysis was based. Comments by K. Stocks, S. Kevin, and 2 anonymous reviewers improved earlier versions of the manuscript.

\section{LITERATURE CITED}

Abeles A, Airame S, Bergen M, Chiang L, Fangman S, Pitterle B (2003) Summary of research programs in the Channel Islands National Marine Sanctuary. Bren School of Environmental Management, UCSB; Channel Islands National Marine Sanctuary; California Department of Fish and Game, Santa Barbara, CA. Available at: www.cinms.nos.noaa.gov/marineres/PDF/sum_research.pdf

Airame S, Dugan JE, Lafferty KD, Leslie H, McArdle DA, Warner RR (2003) Applying ecological criteria to marine reserve design: a case study from the California Channel Islands. Ecol Appl (Suppl)13:S170-S184

Allison GW, Lubchenco J, Carr MH (1998) Marine reserves are necessary but not sufficient for marine conservation. Ecol Appl 8:S79-S92

Bohonak AJ (1999) Dispersal, gene flow, and population structure. Q Rev Biol 74:21-45

Botsford LW, Hastings A, Gaines SD (2001) Dependence of sustainability on the configuration of marine reserves and larval dispersal distance. Ecol Lett 4:144-150

Caley MJ, Carr MH, Hixon MA, Hughes TP, Jones GP, Menge B (1996) Recruitment and the local dynamics of open marine populations. Annu Rev Ecol Syst 27:477-500

California Department of Fish and Game (2002) Descriptions and evaluations of existing California Marine Protected Areas. June 1, 2002. Available at: www.dfg.ca.gov/mrd/ mlpa/analysis.pdf

Channel Islands National Marine Sanctuary (CINMS) (2005) Marine reserves in the Channel Islands National Marine Sanctuary. Available at: www.cinms.nos.noaa.gov/ marineres/main.html

Colwell RK (2005) EstimateS: statistical estimation of species richness and shared species from samples. Version 7.5 Persistent. Available at: purl.oclc.org/estimates 
Dean D (1978) Migration of the sandworm Nereis virens during winter nights. Mar Biol 45:165-173

Gaines SD, Gaylord B, Largier JL (2003) Avoiding current oversights in marine reserve design. Ecol Appl (Suppl)13:S32-S46

Gallagher ED, Jumars PA, Trueblood DD (1983) Facilitation of soft-bottom benthic succession by tube builders. Ecology 64:1200-1216

Grantham BA, Eckert GL, Shanks AL (2003) Dispersal potential of marine invertebrates in diverse habitats. Ecol Appl (Suppl)13:S108-S116

Gunther C (1992) Dispersal of intertidal invertebrates: a strategy to react to disturbances of different scales? Neth J Sea Res 30:45-56

Hellberg ME (1996) Dependence of gene flow on geographic distance in two solitary corals with different larval dispersal capabilities. Evolution 50:1167-1174

Hewatt WG (1946) Marine ecological studies on Santa Cruz Island, California. Ecol Monogr 16:185-210

Hobson ES, Chess JR (1976) Trophic interactions among fishes and zooplankters near shore at Santa Catalina Island, California. Fish Bull 74:567-598

Kingsford M.J, Leis JM, Shanks AL, Lindeman KC, Morgan SG, Pineda J (2002) Sensory environments, larval abilities and local self-recruitment. Bull Mar Sci 70: 309-339

Kinlan BP, Gaines SD (2003) Propagule dispersal in marine and terrestrial environments: a community perspective. Ecology 84:2007-2020

Largier JL (2003) Considerations in estimating larval dispersal distances from oceanographic data. Ecol Appl (Suppl)13:S71-S89

Levin LA, Huggett DV (1990) Implications of alternative reproductive modes for seasonality and demography in an estuarine polychaete. Ecology 71:2191-2208

Lunchenco J, Palumbi SR, Gaines, SD, Andelman S (2003) Plugging a hole in the ocean: the emerging science of marine reserves. Ecol Appl (Suppl)13:S3-S7

Lynn RJ, Simpson JJ (1987) The California Current system: the seasonal variability of its physical characteristics. J Geophys Res C 92:12947-12966

Palumbi SR (2003) Population genetics, demographic connectivity, and the design of marine reserves. Ecol Appl (Suppl)13:S146-S158

Parker T, Tunnicliffe V (1994) Dispersal strategies of the biota of an oceanic seamount: implications for ecology and biogeography. Biol Bull 187:336-345

Ranasinghe JA,Montagne DE, Smith RW, Mikel TK, Weisberg SB, Cadien DB, Velarde RG, Dalkey A (2003) Southern California Bight 1998 regional monitoring program: VII benthic macrofauna. Southern California Coastal Water Research Project, Westminster, CA. Also available at: ftp://ftp.sccwrp.org/pub/download/PDFs/bight98benthic.pdf

Roberts CM, Branch G, Bustamante RH, Castilla JC and 8 others (2003) Application of ecological criteria in selecting marine reserves and developing reserve networks. Ecol Appl (Suppl)13:S215-S228

Roughgarden J, Iwasa Y, Baxter C (1985) Demographic theory for an open marine population with space-limited recruitment. Ecology 66:54-67

Editorial responsibility: Otto Kinne (Editor-in-Chief), Oldendorf/Luhe, Germany
Rumrill SS (1990) Natural mortality of invertebrate larvae. Ophelia 32:163-198

Sala E, Aburto-Oropeza O, Paredes G, Parra I, Barrera JC, Dayton PK (2002) A general model for designing networks of marine reserves. Science 298:1991-1993

Shanks AL, Grantham BA, Carr MH (2003) Propagule dispersal distance and the size and spacing of marine reserves. Ecol Appl (Suppl)13:S159-S169

Shull DH (1997) Mechanisms of infaunal polychaete dispersal and colonization in an intertidal sandflat. $J$ Mar Res 55:153-179

Snelgrove PVR, Butman CA (1994) Animal-sediment relationships revisited: cause versus effect. Oceanogr Mar Biol Annu Rev 32:111-177

Stehlik LL, Meise CJ (2000) Diet of winter flounder in a New Jersey estuary: ontogenetic change and spatial variation. Estuaries 23:381-391

Stockhausen WT, Lipcius RN, Hickey BM (2000) Joint effects of larval dispersal, population regulation, marine reserve design, and exploitation on production and recruitment in the Caribbean spiny lobster. Bull Mar Sci 66:957-990

Strathmann RR (1985) Feeding and nonfeeding larval development and life-history evolution in marine invertebrates. Annu Rev Ecol Syst 16:339-361

Swearer SE, Shima JS, Hellberg ME, Thorrold SR and 6 others (2002) Evidence of self-recruitment in demersal marine populations. Bull Mar Sci (Suppl)70:251-271

Taylor CA (2004) Patterns of early-stage pelagic dispersal and gene flow in rockfish species from the Southern California Bight. PhD dissertation, University of California San Diego, San Diego, CA

Thrush SF, Whitlatch RB, Pridmore RD, Hewitt JE, Cummings VJ, Wilkinson MR (1996) Scale-dependent recolonization: the role of sediment stability in a dynamic sandflat habitat. Ecology 77:2472-2487

Thurrold SR, Jones GP, Hellberg ME, Burton RS, Swearer SE, Neigel JE, Morgan SG, Warner RR (2002) Quantifying larval retention and connectivity in marine populations with artificial and natural markers. Bull Mar Sci (Suppl)70:291-308

Todd CD (1998) Larval supply and recruitment of benthic invertebrates: Do larvae always disperse as much as we believe? Hydrobiologia 375:1-21

Waldbusser GG, Marinelli RL, Whitlatch RB, Visscher PT (2004) The effects of infaunal biodiversity on biogeochemistry of coastal marine sediments. Limnol Oceanogr 49:1482-1492

Whitlatch RB, Lohrer AM, Thrush SF, Pridmore RD, Hewitt JE, Cummings VJ, Zajac RN (1998) Scale-dependent benthic recolonization dynamics: life stage-based dispersal and demographic consequences. Hydrobiologia 375/376: $217-226$

Wilson WH (1991a) Sexual reproductive modes in polychaetes: classification and diversity. Bull Mar Sci 48:500-516

Wilson WH (1991b) Competition and predation in marine soft-sediment communities. Annu Rev Ecol Syst 21: $221-241$

Zar JH (1973) Biostatistical analysis, 4th edn. Prentice Hall, Upper Saddle River, NJ

Submitted: December 15, 2004; Accepted: December 8, 2005 Proofs received from author(s): June 6, 2006 